\title{
Research on the Construction of Low-Carbon Culture in Higher Vocational Colleges based on the Internet Era
}

\author{
Huijuan Xie ${ }^{1, a}$, Wei She ${ }^{2, b}$ \\ ${ }^{1}$ Hainan College of Economics and Business, Haikou, 571127, China \\ ${ }^{2}$ Hainan Institute of Science \& Technology, Haikou, 571126, China \\ a360088369@qq.com, b694394619@qq.com
}

Keywords: Smart Campus; the Higher Vocational Colleges; Low-Carbon Culture; Low-Carbon Economy

\begin{abstract}
Low-carbon culture is a kind of culture with green and environmental protection and sustainable development. With the development of the Internet the higher vocational colleges that develop the applied talents will be good for the development of low-carbon economy, advocating low carbon culture, and promoting adjustment of economic structure.
\end{abstract}

\section{Introduction}

The students in the higher vocational college will become the main force in the low-carbon culture circulation, and the important strength to promote the low-carbon economy development. Smart campus construction which is the embodiment of the college low-carbon construction will lay a foundation for low-carbon culture in the colleges. Whether the students in the higher vocational colleges are aware of the low-carbon will be directly related to the development of low-carbon economy in China and has the special significance.

\section{The Basic Theory of Low Carbon Culture on Campus}

Low-carbon that means lower greenhouse gases (carbon dioxide) emissions advocates lower energy consumption and lower pollution. Low carbon culture refers to achieving the consciousness and behavior of the lower-carbon consumption and emissions in the people's life and production practice. Low carbon campus construction was put forward based on the development of low-carbon economy. In a certain sense low carbon campus advocate the paperless teaching in the campus in order to reduce the use of paper books in the teaching and increase the intensity of electronic teaching for the environmental protection [1]. The low carbon education refers to take measures to reduce carbon dioxide emissions, conserve energy and protect environment in all aspects of education, and actively use the digital campus management to improve the management efficiency and save the cost [2].

The low carbon theory provides a theoretical basis for cultivating and constructing of low carbon culture in higher vocational colleges, and is helpful for the students to set up the concept of low carbon.

\section{Analysis of the State of the Cultivating and Constructing Low Carbon Culture in Colleges and Universities in China}

The Development Process, Main Achievements and Experiences of the Construction of Low Carbon Culture in Chinese Colleges and Universities

The United Nations Climate Change Conference was hold in the Copenhagen, the Danish capital, in December 2009, and considered as a very important effort to restrain global warming. With the Copenhagen world climate conference held, Chinese colleges and universities began to respond to the national low carbon economy development $l$ call and practice low-carbon life.

In 2004 Haidian District of Beijing hold a series of activities on "energy-saving and emission-reduction into institutions, communities and schools" in the Peking University, that 
created campus poster design matches on "Low-carbon Haidian, Green Home" as the theme, showed students' genuine interest on loving energy saving, environmental protection and Haidian, thus brought energy saving and environmental protection to the campus, the classroom and the mind[3]. South China University of Technology, Anhui University, HeFei University of Technology and other colleges etc have made remarkable achievements through in variety of ways.

With the development of network information, the network has become an effective way to propaganda the low carbon culture. Since 2012 the research on the construction of low carbon digital campus has been developed respectively, because digital campus construction can realize the integration and optimization of resources. According to the current situation and problems of the construction of digital campus in Colleges and universities, combining with low carbon education concept, the unified user identity authentication system and the promotion of wireless campus network were proposed, that is to create a suitable digital campus environment for the new environment [4].

\section{Problems in the Construction of Low Carbon Campus Culture in Colleges and Universities}

At present, the phenomenon of waste of resources in colleges and universities which are one of the major energy customers and shoulder much greater responsibilities in energy saving and emission reduction is very serious.

The construction of Low Carbon Campus Culture in higher vocational colleges is based on the low carbon campus culture construction, and the second is to strengthen the cultural awareness of Low Carbon Campus in higher vocational colleges. The construction of Low Carbon Campus Culture in higher vocational colleges, firstly, is based on the low-carbon campus construction, and secondly is to strengthen the awareness of low-carbon campus cultural in higher vocational colleges.

Compared with foreign universities, the construction of low-carbon culture on campus in China is still in the early stage, and is restricted by many kinds of factors. There are the following problems such as:

1) The lower Digital Campus Resource Sharing

At present, although most of the higher vocational colleges that have constructed the digital campus lack of awareness of the digital campus and do not play a practical role on the campus of low-carbon construction because serious scattered resources, low data sharing and allocation of bloated configuration still exist.

\section{2) Strengthening the Awareness of Saving in Higher Vocational Colleges}

With the development of wireless network and communication, mobile phone has become the college students' necessary communication tools. Most of the higher vocational colleges cannot advertise the low-carbon culture with the network. Students lack of effective ways to obtain the low-carbon knowledge.

The most important task of the low carbon culture construction is to establish the low-carbon values. The concept of low carbon development should be integrated into the campus values. Campus culture of low carbon education is an urgent task

\section{A wider meaning to Cultivation and Construction of Low-Carbon Culture in Higher Vocational Colleges}

The higher vocational colleges has over 1000 students, and transport 10 million highly skilled personnel to the society accounting for $60 \%$ of the new employment population, have an important effect on example of social practice and penetration. Entering the higher vocational colleges is an effectual way for rural children to receive higher education. The training and construction of low-carbon culture in higher vocational colleges will help establish low carbon awareness of rural people in China, cultivate low carbon behavior of farmers, and improve the overall quality of farmers. 


\section{Speeding up the Low-Carbon Consumption}

Therefore, to develop low carbon economy and to fulfill harmonious coexistence and common development between economy, society and nature is an inevitable choice for people in the times of post-industrialization, and it shows clearly a correct direction for sustainable development and permanent prosperity of people [5]. With the development of the Internet, college students have become the major part of network consumption in our country, grow into a low carbon consumption habit according to students' attitudes on low carbon consumption. Calling for low carbon products, selecting online consumption, reducing carbon emissions, and actively advocating low-carbon consumption and promoting low-carbon consumption are to promote the development of low carbon economy.

\section{Raising Awareness of Low-Carbon Emission}

Students in the higher vocational colleges are an important part of college students in our country. Improving the students' low carbon consciousness in higher vocational colleges is good for improving the national low-carbon awareness. The contemporary vocational college students in the 1990s are more likely to accept new conceptions and things and become a social group. It is an important part of the world. The amount of carbon dioxide emission from all aspects of daily life for per person is shown in Fig 1 per year by the national energy saving and emission reduction calculator.

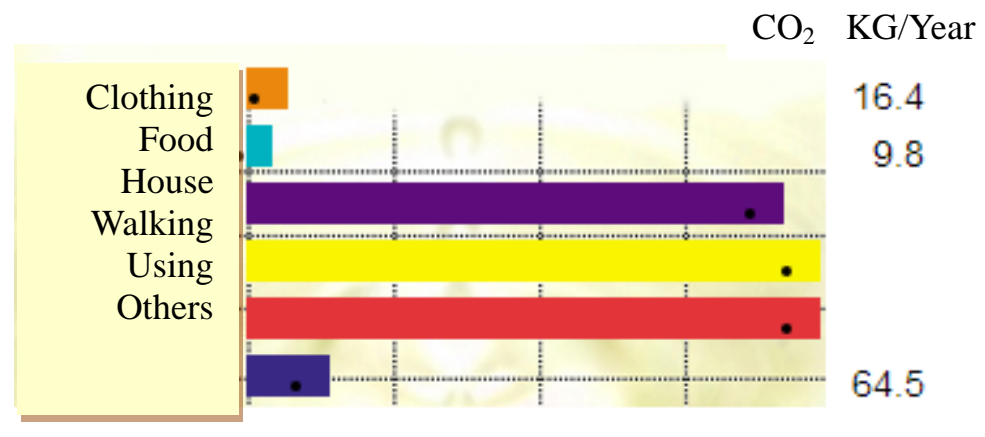

Fig 1 the Amount of Carbon Dioxide Emission

\section{The main Characteristics of the Cultivation and Construction of Low Carbon Culture in Higher Vocational Colleges with the Internet Plus}

\section{The Low-Carbon Construction with the Internet}

Server virtualization and cloud computing resource pool manage the communication of more management platforms (such as: academic management platform, student management platform, library management platform, system, course selection system, etc.), integrate data resources and embody the green energy-saving building in the development of higher vocational colleges archiving information.

Digital campus which has features of rich resources, integrating a variety of application systems, and integrating related business highly, can optimize teaching, research, management and service by integrating information technology and teaching practice[2].

\section{The Low-Carbon Teaching with the Internet}

The higher vocational colleges should develop a low-carbon culture education team of teachers, who can bring the low carbon knowledge into the classroom, set up related low carbon general courses, spread and inherit the low carbon culture.

Virtual cloud should be applied and less paper was used in the teaching because the Laptops, mobile phones and iPad were used for the signature, answering, polling and testing.

\section{Promotion Low Carbon Culture with the Internet}

The knowledge on energy saving and low-carbon should be promoted by Microblog, WeChat and MicroMovie etc in the National Low Carbon Day to spread the knowledge related to climate change and promote the construction of low carbon culture in Campus. 
Methods of cultivating and constructing low carbon culture in Higher Vocational Colleges with the Internet

\section{Cultivation of Students' Low Carbon Culture aAwareness in Higher Vocational Colleges Revving up Publicity}

Cultivation of students' low carbon consciousness in higher vocational colleges has become the most important task because of the necessity and urgency of low carbon construction in University and the main force of Chinese ecological civilization construction in the future.

Firstly, the higher vocational colleges should establish and improve rules and regulations about low carbon culture.

The Higher Vocational Colleges established the organizational structure and Implement the low carbon management system to increase energy efficiency. The rules and regulations related to the construction of low carbon culture on campus should be promoted by Website, micro-blog and WeChat.

Secondly, students should be trained for setting up the social responsibility consciousness of low carbon environmental protection

Under the global climate warming, setting up the social responsibility consciousness of low carbon environmental protection is one of the important measures to develop low carbon economy in China. Students in Higher Vocational Colleges should be encouraged to establish environmental awareness and social responsibility by the school education and take an active part in environmental protection activities.

Third, the Higher Vocational Colleges should Cultivate students' low carbon consumption.

Students in higher vocational colleges will be an important part of social consumer groups. The low carbon consumption should be advocated to eliminate the waste of resources caused by blind consumption. Advocating rational consumption and setting up the concept of low carbon consumption can reduce the carbon emissions to the minimum.

The Construction of Hardware Reflects the Low Carbon Culture in Higher Vocational Colleges

1) Digital Campus Construction

The digital campuses take technology of highly developed computer Internet plus as the core, and take sharing of information and knowledge resources as a means. Internet plus, digital and intelligent new education and the study and research on Internet plus platform are a kind of virtual education environment which can optimize the teaching resources [6].

Digital campus construction that is the foundation of paperless teaching and meets the development of low carbon economy, effectively implement resource sharing and reduce the work intensity of managers.

\section{2) Wisdom Campus Construction}

The wisdom campus that was put forward aimed at the lower utilization rate of digital resources and sharing rate of server resources had great practical significance to the construction of Low Carbon Campus in higher vocational colleges. The wisdom campus construction is one of the embodiments of the low-carbon culture cultivation and construction of higher vocational colleges under the background of the Internet plus.

It was aimed at the disadvantages of digital campus construction, the study anyplace and anytime could be come true by the wisdom campus. Mobile smart campus which is one of the important components, realizes the unified and wisdom management, integrates the server resources, and helps to build a more energy-efficient Vocational Campus.

\section{Conclusion}

In summary, the construction of low-carbon culture in the higher vocational colleges can inject fresh energy for the construction of campus culture, realize the sustainable development of the low carbon culture construction in Higher Vocational Colleges, and cultivate the main force for the low-carbon culture in our country. 


\section{Acknowledgement}

In this paper, the research was sponsored by the 12th Five-Year Education and Scientific Research Project of the Vocational College Cultural Quality Committee of the Education Department (Project No.WH125YB36) and Youth Fund Project of Hainan College of Economics and Business (Project No. hnjm2015108).

\section{References}

[1] Nan Yuan, Runcheng Bi. the Low Carbon Campus Construction in the Low Carbon Age: Concept, Characteristics and Countermeasures. Journal of Shanxi Normal University (Natural Science Edition), 2010,25:43-46

[2] Jiahou Li. the Road of Information of Low Carbon Education. Information Technology Education in China,2010(104):13-17

[3]Information on http://www.hddrc.gov.cn/rdzt/dthd/sjhd/jxy/201001/t20100118_178291.htm,2010

[4] Hongyuan Yu, Ling Zhao. Construction of Low Carbon Digital Campus in Colleges and Universities, Hunan Agricultural Machinery ,2010,37(5):173-174

[5] Xiangsheng Dou, The essence, feature and role of low carbon economy, Environment, Development and Sustainability,2015,17(1):123-136.

[6] Jun Cao, Hai Wang, Xuguang Liu. Research on the Construction of Low Carbon Digital Campus. Teaching of Forestry Region, 2013(11):11-14. 